\title{
UNCONVENTIONALS IN EUROPE: BEST PRACTICE VS. WORST CASE - THE CONFLICT BETWEEN FACTS AND PUBLIC PERCEPTION
}

\author{
NIEKONWENCJONALNE W EUROPIE. \\ KONFLIKT POMIĘDZY FAKTAMI \\ A PERCEPCJĄ PUBLICZNĄ
}

\begin{abstract}
In spite of great progress in energy efficiency and in the development of renewable energy the world is likely to need significant amounts of fossil fuel throughout this century and beyond (the share of fossil fuels in the world mix has remained at about $86 \%$ of primary energy from 1990 to today). Gas, being the by far cleanest fossil fuel is the ideal bridging fuel to a world with predominantly renewable supplies. Thanks to the recent perfection of unconventional technologies there is no shortage of gas for this bridging function for at least the next 100-200 years. EASAC and several other European Institutions, notably the German Academy of Technical Sciences (acatech) have in the last few years carried out expert studies to assess the alleged environmental risks of unconventional hydrocarbon exploration and production. All these studies have, in agreement with other competent studies worldwide, come to the conclusion that there exists no scientific reason for a ban on hydraulic fracturing. With good practices, clear standards and adequate control the method causes no enhanced risks to the environment or the health of humans. Special attention has to be paid to the surface handling of drilling and fracking fluids. In Europe alone many thousand frac jobs have been carried out by the industry in the last 60 years without any severe accidents. The mishaps in North America have largely been the cause of unprofessional operations and human error. Especially in places with high air pollution, like many megacities of Asia, natural gas has to be seen as a unique chance to achieve a rapid improvement of the air quality and a significant reduction of $\mathrm{CO}_{2}$ emissions. This is also true for Europe where especially the use of domestic natural gas brings important benefits to the environment. The alternative to gas is in many regions of the world an increased consumption of coal, with all negative consequences.
\end{abstract}

Keywords: hydraulic fracturing, natural gas, unconventional gas, global energy, environment, global climate, methane, $\mathrm{CO}_{2}$, coal, greenhouse gas, induced seismicity

\section{The size of the global energy challenge}

A forecast of global energy demand is difficult but several recent estimates hint to a doubling of global energy consumption within 50 years. This requires a considerable slowdown of the recently observed growth rate, having reached $28 \%$ between 2003 and

\footnotetext{
${ }^{1}$ Swiss Association of Energy Geoscientists, Holbeinstrasse 7, 4051 Basel, Switzerland

${ }^{2}$ EASAC (European Academies' Science Advisory Council) Expert Group on Shale Gas Extraction, Jägerberg 1, 06108 Halle (Saale), Germany, email: peterburri.geol@bluewin.ch
} 
2013. Renewable energy (without hydro) grew in the last 10 years by an impressive $316 \%$; nevertheless this steep growth was able to cover only $7.6 \%$ of the additional energy consumption (with hydro some 17\%). As a consequence of this shortfall, $83 \%$ of the growth had to be covered by an increase in fossil fuel production since there was no growth in nuclear. The share of renewables (without hydro) in global energy supply is today only $2.2 \%$. Renewables are unfortunately still very far away from being able to cover the growth in energy demand, let alone replace fossil fuels (the share of fossil fuels in the global primary energy mix has remained at some 86\% from 1990 to 2014 [1]. The world will require a broad mix of energies since no single source will be able to cover the world's energy needs in this century, and we need in addition a much higher energy efficiency. Unconventional hydrocarbons, especially gas, will have to play a major role in the transition.

\section{The EASAC study and the position of European Scientific Institutions}

Unconventional hydrocarbons and hydraulic fracturing (HF) have triggered a very emotional debate in Europe and scientific opinions are often ignored. In an effort to remedy this, several Earth Science Institutions and Academies of Science in Europe have therefore issued position papers and recommendations. Most recently acatech (German Academy of Technical Sciences) has produced a large position paper on the topic [2]. A position paper was also produced in 2014 by EASAC [2]. The project group for the EASAC paper, met for a workshop at Lublin in June 2015.

The EASAC study with the title: "Shale gas extraction issues of particular interest to the European Union", did not carry out any new in depth technical studies but focused on the following questions which are of main interest to European countries:

Impact of exploitation of shale gas in highly populated areas?

- Effect on greenhouse gas emissions?

- How to address public fears and concerns?

The results of this EASAC assessment can be summarized as follows:

○ There is no scientific or technical ground to ban shale gas extraction using hydraulic fracturing

- Existing Best Practices, like replacement of harmful chemicals or full disclosure of additives, have greatly reduced the environmental footprint and increased transparency

- The conflict on land use has been mitigated by cluster drilling

- Well integrity and long term sealing of wells (after abandonment) needs special attention

- Greenhouse gas: Elimination and prevention of potential methane leaks are a must to make gas environmentally acceptable

○ Minimizing noise and traffic emissions is very important to public

- Use of resources, mainly water, remains a main concern to public. Mitigation is necessary through recycling and possibly non-water based frac fluids (gas fracs?)

- Europe's regulatory system on conventional gas extraction provides already an adequate framework for minimizing the impact on HSE (only adaptions are necessary)

- Pilot projects must be carried out in Europe to demonstrate best practice - with close monitoring by authorities - to create trust 
- Communities and all stakeholders need to have an informed understanding of the technology. Communities must benefit from gas production

- The potential of shale gas for Europe is considerable but is no "simple silver bullet" to address Europe's energy security and the challenge of climate change

In the course of the study by Deutsche Akademie der Technikwissenschaften in Germany, the worldwide assessments of Shale Gas Development were screened. It is noteworthy that all scientific organizations with relevant knowhow in this field (deep subsurface geology and geophysics, drilling technology, reservoir engineering and deep subsurface engineering) reject a ban on hydraulic fracturing but recommend adequate regulations and control [1-10]. Unfortunately, this advice has been largely ignored by politicians, authorities and media.

\section{Hydraulic fracturing technology: Criticism and facts}

Criticism of shale gas exploration and production has surfaced in Europe mainly after the film "Gasland" which claimed major environmental damage as a consequence of shale gas exploitation in the US. The film attacked primarily alleged water contamination by drilling- and fracking fluids and methane. Many of the accusations, presented by "Gasland", have in the meantime proven to be incorrect by independent investigators, including the US Environmental Protection Agency [3] and in most cases a causal link to the gas operations could not be proven. However, some of the issues raised by other critical observers have identified genuine areas of concern and inacceptable mistakes were made primarily during the early «goldrush» boom of unconventional gas exploration in the US. Most of the problems have in the meantime been resolved through better technology and higher operational standards (partly triggered by more severe regulations, partly through self-control of industry in an effort to keeping the license to operate). It has to be noted that the majority of the critical points raised, have never been issues in Europe, given the fact that European legislation for oil and gas operations had already introduced much stricter controls and regulations for conventional drilling, well integrity and hydraulic stimulations. In spite of this - and ignoring some 60 years extensive and problem-free European experience with hydraulic fracturing - the public discussion is being dominated by emotions and surprisingly little rational argumentation. This paper tries to contribute to redressing this imbalance.

The main issues of public criticism of the hydraulic fracturing technology and the corresponding factual evidence can be summarized as follows:

Hydraulic fracturing creates artificial fractures that can reach the surface or intersect shallow aquifers of drinking water, thus creating pathways for possible pollutants (Fig. 1)

- Hydraulic fracturing can be well controlled by microseismic measurements that allow an exact mapping of the horizontal and vertical extent of the created fissures.

- The volume of fractures created cannot exceed the volume of the fluid injected. Given the limited volumes injected, fractures extend over few $100 \mathrm{~m}$ at most; creating fractures of $1000 \mathrm{~m}$ or more length is physically impossible with the given injection volumes.

- There is no proven case of an artificial fracture reaching surface from depths of $>1000 \mathrm{~m}$. 

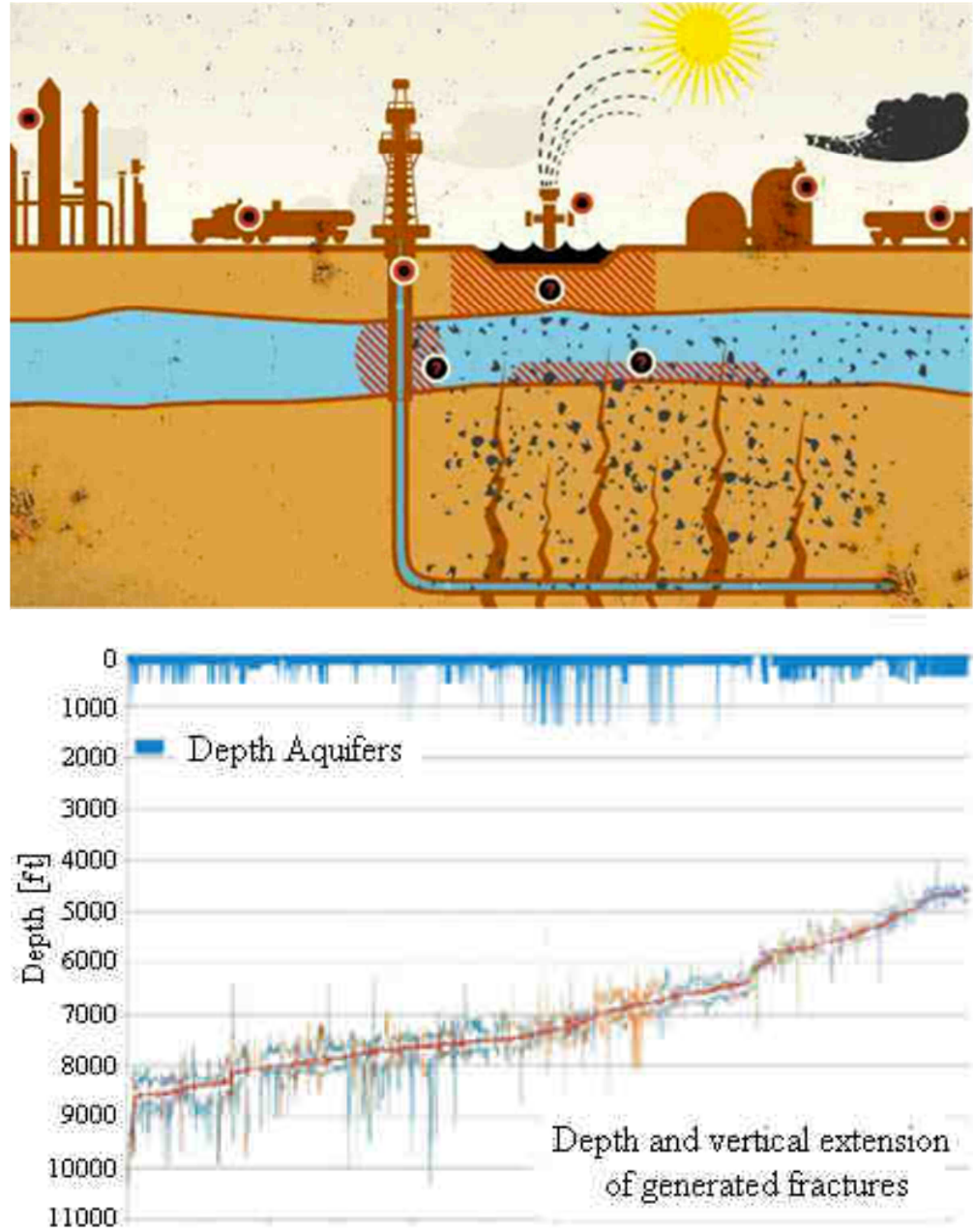

Fig. 1. Top: Alleged pollution by hydraulic fracturing according to film "Gasland" with fracturing a few metres below aquifer. The illustration has nothing to do with reality. Below: depth of aquifers and depth in the Barnett Basin (Texas) with actual fractures measured by microseismic. Note distance of several 1000 feet between fracs and aquifers

- The additives used so far in Europe (generally $<1 \%$ of the frac fluid) belong to the "Low risk substances" for drinking water. More recently Exxon Germany has further reduced the additives to two substances, both non-toxic and biodegradable. HF can today be carried out without any harmful additives and thus without risk to groundwater.

- Where contaminations have happened in the past, they are almost exclusively caused by negligent surface handling, poor well integrity [5].

- The top federal water experts in Switzerland have come to the conclusion that, if properly done, HF causes no risk to groundwater, justifying a ban of the technology [6]. 
- Disclosure of all additives needs to be compulsory as it is in many US states and some parts of Europe [1, 2].

\section{Hydraulic fracturing uses large quantities of freshwater}

- HF uses several $100 \mathrm{~m}^{3}$ of water per frac in gas wells and thus up to several $1000 \mathrm{~m}^{3}$ of water per well.

- HF does not require fresh water. A significant part of the water is recovered during backflow. Several companies in the US recycle today up to $100 \%$ of the recovered water. Some companies experiment with water free HF, using gas instead (propane).

- Burning methane produces $\mathrm{CO}_{2}$ and water with an overall positive contribution to the water cycle. The gas from an average Marcellus shale gas well produces over its lifetime some between $2.5 \mathrm{x}$ and $15 \mathrm{x}$ the volume of water used for drilling and fracturing, depending on how much of the water is recovered in the flowback (AAPG Convention 2014, Panel on Shale Gas).

\section{Hydraulic fracturing causes earthquakes}

- Fracturing in rocks causes microseismicity, whenever shear movements occur. The seismic magnitude correlates directly with fracture size and injected fluid volumes and lies in shale fracs generally below M 1, ie far below levels noticed by human beings. The highest recorded seismicity in hydraulic fracturing of shales measured M 2.3 [3].

- Although over 3 million frac jobs have been carried out in sediments worldwide, no damage quakes are known. Significant induced seismicity has, however, been observed where large quantities of fluids are re-injected into the subsurface ( $e g$ the recent midcontinent quakes in Oklahoma) or where large shear fracturing of basement rocks has been undertaken ( $\mathrm{g}$ fracturing of crystalline rocks for geothermal heat exchangers).

\section{Unconventional gas production leads to excessive land use}

- Excessive land use has been a problem only in the early days of the shale gas boom when vertical wells were drilled. Today land use is no longer an issue since cluster drilling is the norm and up to 30 wells are being drilled from one location. $10 \mathrm{~km}^{2}$ of subsurface reservoir or more can today be drained from a single location.

- Gas production has a much smaller footprint than most renewable energies. A typical gas cluster in N-Germany produces about $300000 \mathrm{kWh}$ on a surface of $0.01 \mathrm{~km}^{2}$. Producing the same amount of energy requires alternatively (source: erdgasproduktion-in-deutschland.de):
○ $400 \mathrm{~km}^{2}$ of maize crop for biogas
- $25 \mathrm{~km}^{2}$ land for 200 large wind turbines
- $19 \mathrm{~km}^{2}$ of solar panels

Hydraulic fracturing and unconventional gas production causes large quantities of methane to leak into groundwater, soil and atmosphere

- Methane is a powerful climate gas; over a time frame of 100 years it is $28 \mathrm{x}$ more effective than $\mathrm{CO}_{2}$. Methane emissions must therefore be avoided.

- Very large volumes of methane enter the atmosphere through natural processes. From source rocks and coal seams as well as through bacterial activity large quantities of 
methane (up to several $1012 \mathrm{of}^{3}$ ) are released over geological times. The presence of methane seeps and methane in sediments of gas generating basins is therefore a normal, natural phenomenon (the infamous burning gas tap in the film "Gasland" produces natural gas from a coal seam intersecting the water well).

- Nevertheless, additional methane emissions through gas production and distribution must be excluded. Where high drilling standards, good well integrity and good maintenance are enforced, methane leaks are not a problem. In Germany the natural gas industry contributed in 2012 less than $0.1 \%$ to the total methane emissions of Germany [3].

\section{Hydraulic fracturing leads to heavy traffic and noise}

- Trucking remains an issue during drilling and HF operations, it can, however be greatly used through recycling and re-use of the flowback and through the use of temporary water pipelines. Producing fields cause very little traffic and sound emissions.

- Cluster drilling allows siting of wells away from homes or other sensitive areas.

Wells stimulated by hydraulic fracturing have high decline rates. Shale gas production requires continuous high levels of drilling and unconventional gas is, therefore, not sustainable and largely uneconomic

- Unconventional production requires ideally an oil price $>60 \$ / \mathrm{bbl}$ (oil barrels) and for gas > \$4-5 /141-177 $\mathrm{m}^{3}$ to be fully economic and allow further investments. Both criteria are at present price levels not given in the US and many of the smaller companies are economically struggling.

- Production decline of unconventional wells is steeper than in most conventional production but lower production levels can thereafter be maintained for many years, partly beyond 10 years. There has in recent years been an almost exponential improvement in the productivity per well: better completion technologies and a focus on geological sweet-spots have between 2008-2014 led to increases in the ultimate recovery per unconventional well of up to a factor 10 or more (US EIA Drilling Productivity Report, March 2014). Rig numbers for unconventional gas drilling have decreased since 2008 by $80 \%$, while the gas production was still rising in 2015 .

\section{Gas production and environment}

The large volumes of new gas resources that have been added worldwide in the past years, are a chance for the environment. Some $75 \%$ of the global $\mathrm{CO}_{2}$ emissions are being caused by power generation and traffic; in both cases substitution of coal or diesel/gasoline by natural gas is technically easy to achieve and economically gas is today competitive with these fuels. Proof for successful substitution are the US, where from 2008 to $2013 \mathrm{CO}_{2}$ emissions have been reduced by $12 \%$ and have been falling further since. Although not signatory of the Kyoto Protocol, the US are one of the very few countries that will achieve the Kyoto target of reducing $\mathrm{CO}_{2}$ emissions below the levels of 1990. Per capita the $\mathrm{CO}_{2}$ emissions of the US are at present at the level of the mid 1960's. A main cause of this dramatic improvement is the substitution of coal by natural gas in power generation (Fig. 2). 

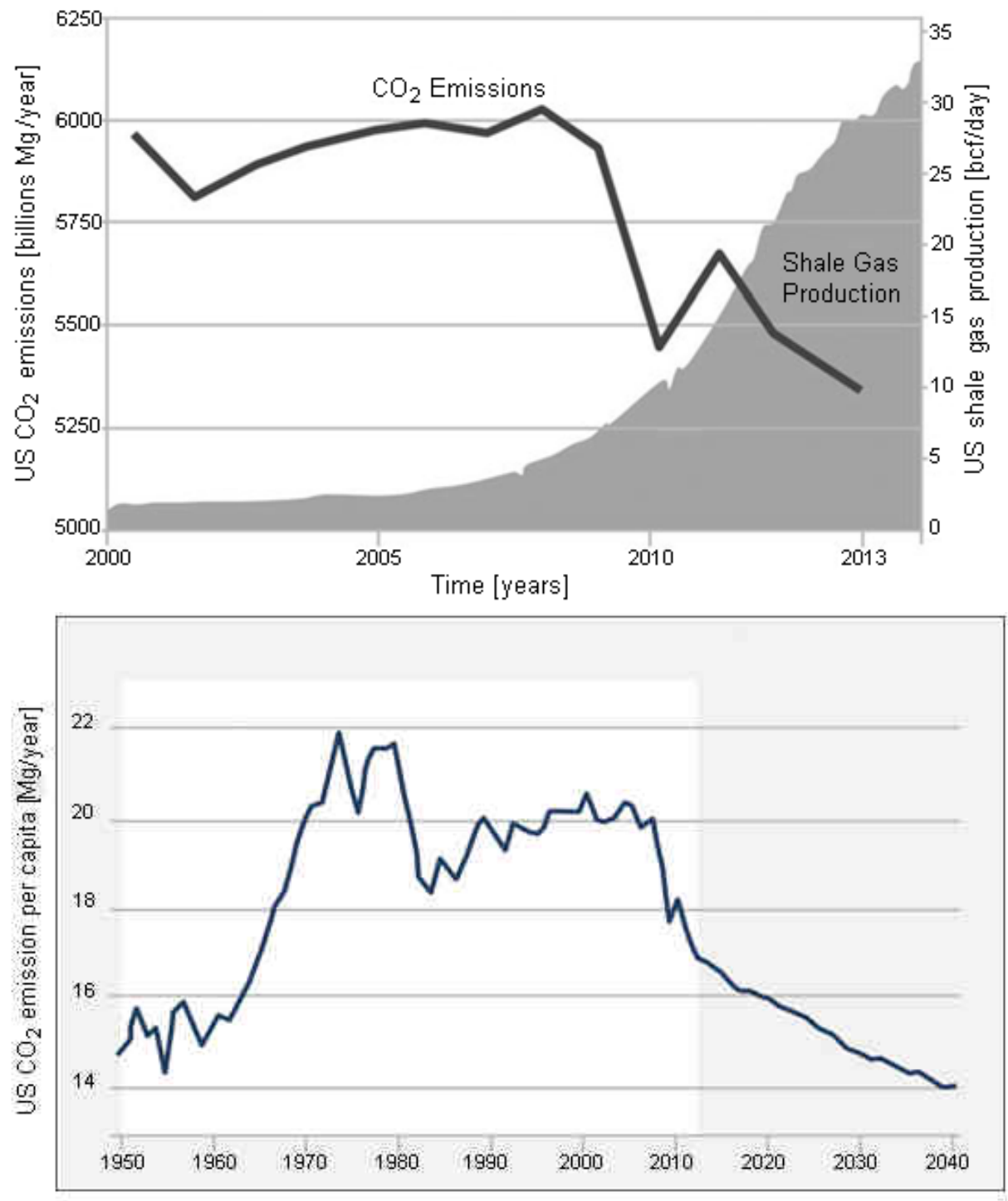

Time [years]

Fig. 2. US $\mathrm{CO}_{2}$ emissions and shale gas production. The availability of shale gas allows emission reductions not achieved in any other industrialized country. The $1990 \mathrm{CO}_{2}$ emissions of the US were 5.100 million $\mathrm{Mg}$ (Kyoto Protocol target) [11]

Today's discussion focuses too narrowly on greenhouse gases; an equally severe and often more urgent problem, especially in the mega cities of Asia, is the poor air quality caused by sulfur, carbon monoxide and mainly fine particle dust. Beijing has registered in 2014 fine dust concentrations up to 40 times the health risk level defined by the World Health Organization (WHO). According to a press release by WHO in 2014 there are 
7 million deaths per year caused by air pollution. A large part of this pollution is created by coal.

Renewable energy plays an increasingly important role in our future energy supply but we are still decades away from only covering the increase in energy demand through renewables, let alone replace fossil fuels. The share of fossil fuels in the global energy mix has decreased since 2004 by $1 \%$ only while the absolute volumes have grown by some $28 \%$ $[7,8]$. Unfortunately coal, as the worst polluter has shown the largest growth rates since 2000. A reversal of this trend in the short and mid term is only possible with a deliberate switch to the cleanest fossil fuel: natural gas (Fig. 3).

a)

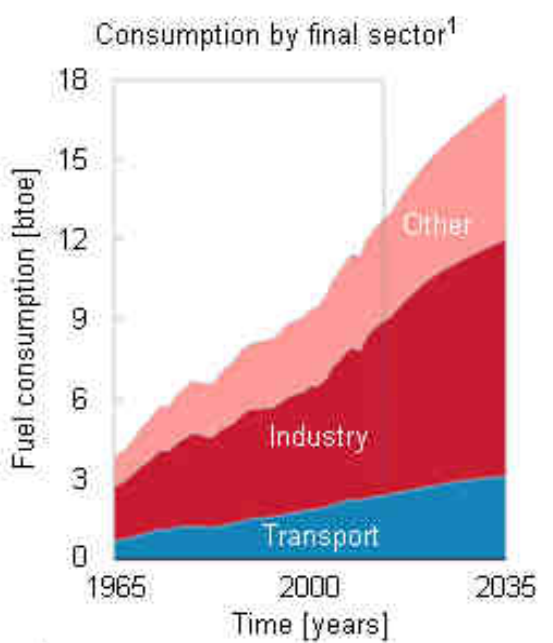

b)

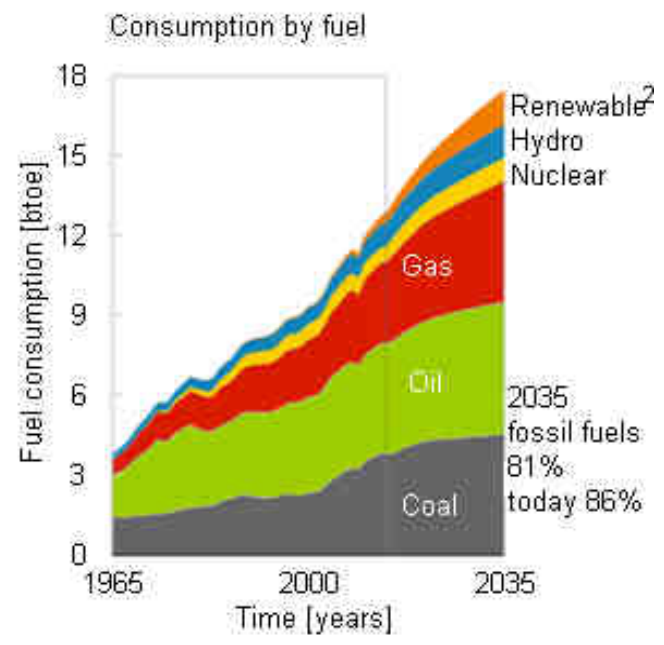

${ }^{1}$ Primary fuels in power allocated according to final sector electricity consumption

${ }^{2}$ Includes biofuels

Fig. 3. a) Global fuel consumption forecast until 2035 [10]. Note that the share of fossil fuels is reduced only minimally by 2035 while actual volumes rise. A further major increase of $\mathrm{CO}_{2}$ emissions from higher coal and oil burning can in the midterm only be prevented through substitution of coal and partly oil by the lower carbon natural gas [10], b) Global main fuel consumption forecast until 2035

Europe covers $25 \%$ of its energy demand with natural gas. With declining own, conventional gas production, Europe is increasingly dependent on imports from Russia, North Africa and by LNG. Europe has, form a geological perspective, a considerable potential for unconventional gas $[8,9]$; a development of these unconventional resources could for many decades prevent a further aggravation of the import dependency. At present there is, however, a strong political and media movement in Europe against domestic gas production. Yet, as long as Europe requires large amounts of gas, economic - and - more importantly - environmental reasons provide strong arguments in favor of domestic gas production:

○ In domestic production we ourselves determine the standards and regulations that guarantee a safe and environment friendly operation. 
- By producing gas close to the consumer, no energy is wasted an no extra $\mathrm{CO}_{2}$ emitted by transporting gas over several $1000 \mathrm{~km}$ from the Sahara or Siberia to Europe.

- With the standards presently applied in W-Europe, the risk of methane emissions is negligible.

\section{Conclusions}

- Clean and safe production of unconventional gas through hydraulic fracturing is possible and is being applied already by several "best practice" companies. Accidents have happened but have been caused almost exclusively by human negligence or substandard equipment and operations. Many thousand frac operations have been carried out in the last 60 years in Europe without any significant mishap.

- No scientific organization or institution with specific knowhow in this field (deep subsurface geology/geophysics, modern drilling technology and subsurface engineering) has so far spoken out in favor of a ban of unconventional gas and hydraulic fracturing. All institutions, including the European Academies of Science are instead advocates of clear standards, regulations and control. Adequate regulations exist already in most European countries but they must be strictly applied and enforced.

- Shale gas will not make Europe independent of energy imports but it could contribute significantly to keep this dependency at more acceptable levels for decades to come.

- As long as Europe requires a large amount of natural gas to cover its energy needs (today 25\%) it makes eminent sense - particularly for environmental reasons - to produce this gas domestically, close to the consumer with minimum waste and emissions.

- In spite of the impressive growth of renewables we will most likely not be able to cover the world's energy needs entirely without fossil fuels in this century. We should therefore use the cleanest fossil energy, gas. The global alternative to this is coal with consequently high levels of air pollution and $\mathrm{CO}_{2}$ emissions.

- While, as EASAC states, gas is not the ultimate solution for the climate challenge, it is the only short to mid term mitigation presently available. The large volumes of new global gas resources, boosted by unconventional finds, provide the world with the unique chance to use gas as a bridge towards a low carbon world.

- The future of Europe's energy security and environment is too important to be left to politicians, administrators and the media: Scientists and engineers must make their voices heard. Europe's biggest resource to master its energy future is creativity. Creativity and scientific innovation are not achieved by banning technologies.

\section{References}

[1] Emmermann R, editor. Hydraulic Fracturing: Eine Technologie in der Diskussion. Deutsche Akademie der Technikwissenschaften; 2014.

[2] EASAC (European Academies Science Advisory Council) 2014: Shale gas extraction: issues of particular relevance to the European Union. http://www.easac.eu.

[3] EPA 2015: External Review Draft, EPA/600/R-15/047a, June 2015. http://www.epa.gov/hfstudy.

[4] SASEG, editor. Swiss Bulletin for Applied Geology. Special volume on Hydraulic Fracturing. Swiss Bull Angew Geol. 2014:19(2). http://www.saseg.ch/cms/images/pdf/Publikationen/Medien/SwissBulletin_22014-lr.pdf. 
[5] Reichetseder P. Clean unconventional gas production: Myth or reality? The role of well integrity and methane emissions. Swiss Bull Angew Geol. 2014;19(2):39-52. http://www.saseg.ch/cms/images/pdf/ Publikationen/Medien/SwissBulletin_2-2014-lr.pdf.

[6] Hartmann D, Meylan B. Fracking in der Schweiz aus Sicht des Grund- und Trinkwasserschutzes. Swiss Bull Angew Geol. 2014;19(2):109-113. http://www.saseg.ch/cms/images/pdf/Publikationen/Medien/ SwissBulletin_2-2014-lr.pdf.

[7] Reinicke K. The role of hydraulic fracturing for the supply of subsurface energy. Swiss Bull Angew Geol. 2014;19(2):5-17. http://www.saseg.ch/cms/images/pdf/Publikationen/Medien/SwissBulletin_2-2014-lr.pdf.

[8] Burri P, Chew K, Jung R, Neumann V. The potential of unconventional gas - energy bridge to the future (with a review of European unconventional gas activities). Swiss Bull Angew Geol. 2011;16(2):3-55. http://www.e-periodica.ch/digbib/view?pid=vsp-004:2011:16.

[9] Burri P. Hydraulic Fracturing - Postscriptum. A geologist's attempt to summarize what we know and where we go. Swiss Bull Angew Geol. 2014;19(2):143-150. http://www.saseg.ch/cms/images/pdf/Publikationen/ Medien/SwissBulletin_2-2014-lr.pdf.

[10] BP 2015: Energy Outlook 2035. http://www.bp.com/energyoutlook. 